\title{
LA RESPONSABILIDAD PENAL POR EL PRODUCTO EN COLOMBIA, PROBLEMAS DE IMPUTACIÓN, DE AUTORIA Y PARTICIPACIÓN*
}

\author{
Jorge Arturo Abello Gual**
}

Fecha de Recibo: 10 de octubre de 2011

Fecha de Aprobación: 7 de diciembre de 2011

Artículo resultado de Investigación

\begin{abstract}
Resumen
El presente artículo busca analizar las tendencias actuales sobre la autoría y la participación en la responsabilidad penal empresarial, utilizando como metodología el estudio de un caso. De esta manera, se analizarán las diferentes formas de autoría y participación, en un caso de responsabilidad penal por el producto, ocurrido en Alemania en la década de los 80's, y que se conoce como el caso de Lederspray.
\end{abstract}

\section{Palabras clave}

Responsabilidad penal sobre el producto, autoría y participación, dolo, culpa, responsabilidad penal empresarial.

\section{CRIMINAL LIABILITY FOR THE PRODUCT IN COLOMBIA, PROBLEMS OF ATTRIBUTION OF AUTHORSHIP AND PARTICIPATION}

\begin{abstract}
This article seeks to analyze the current trends in authorship and participation in corporate criminal responsibility, as a methodology using a case study. In this way, we will analyze the different forms of ownership and participation in a case of criminal liability for the product, which occurred in Germany in the early 80's, and named Lederspray case.
\end{abstract}

\section{Keywords}

Criminal liability on the product, ownership and participation, fraud, fault, corporate criminal liability.

* Este artículo es producto de investigación financiada por el Politécnico Grancolombiano Institución Universitaria.

** Abogado y especialista en Derecho Penal de la Universidad del Norte (Barranquilla); Magíster en Derecho de la Universidad de los Andes. Profesor e investigador del Politécnico Grancolombiano. Correo electrónico: georabello@hotmail.com 


\title{
RESPONSABILIDADE CRIMINAL DO PRODUTO NA COLÔMBIA, OS PROBLEMAS DE ATRIBUIÇÃO DE AUTORIA E PARTICIPAÇÃO
}

\begin{abstract}
Resumo
O presente artigo procura analisar as tendências actuais sobre a autoria e a participação na responsabilidade penal empresarial, utilizando como metodología o estudo de um caso. Desta maneira, analisar-se-ão as diferentes formas de autoria e participação, num caso de responsabilidade penal pelo produto, ocorrido em Alemanha no início dos anos 80, e foi chamado como o caso de Lederspray.
\end{abstract}

\section{Palavras-chave}

Responsabilidade penal sobre o produto, autoria e participação, dolo, culpa, responsabilidade penal das pessoas colectivas.

\section{INTRODUCCIÓN}

Los nuevos fenómenos criminales de la modernidad, le han venido presentando duros retos al derecho penal para combatir la delincuencia organizada: por una parte, la necesidad de evitar la impunidad de ciertas actividades criminales que no se habían previsto en la dogmática penal clásica y por la otra, la de conservar la protección de las garantías legales y constitucionales, tanto del derecho penal general, como las del debido proceso.

En la actualidad uno de los fenómenos criminales que preocupan a la dogmática penal es la de la imputación de la responsabilidad penal al interior de las empresas por la comisión de delitos en y a través de ellas; se menciona incluso que el $80 \%$ de los delitos socioeconómicos son realizados a través de las empresas (Orts y González, 2010, p. 263). Esta preocupación no es infundada, toda vez, que en la mayor parte de los Estados la actividad económica, es decir, la oferta y demanda de bienes y servicios, es desarrollada por sociedades o compañías comerciales y en muchos casos, es incluso obligatoria la constitución de una sociedad mercantil para desarrollar cierta actividad económica, como ocurre en Colombia con los bancos, las empresas prestadoras del servicio de salud, las instituciones de educación superior, entre otras.
Por lo anterior, si la mayor parte de la economía se desarrolla a través de las empresas, es concordante a su vez la tendencia en las organizaciones criminales a desarrollar toda o alguna actividad delictiva a través de empresas, que les sirven de fachada y les permiten evadir la acción de las autoridades penales, debido a que en muchas oportunidades, los verdaderos jefes de dichas organizaciones, ni si quiera aparecen en los papeles de una compañía.

Pero además, así como un individuo (persona natural) en desarrollo de sus actividades normales como conducir, vender un bien $u$ ofrecer un servicio, puede ocasionalmente cometer un delito, por ejemplo, cuando un sujeto conduce su vehículo y atropella a un transeúnte u ocasiona un accidente, las empresas (personas jurídicas) como entes que agrupan a varias personas naturales para desarrollar una actividad económica, también pueden en desarrollo de su actividad empresarial, infringir ocasionalmente la norma penal por la actuación de las personas naturales que la conforman, piénsese por ejemplo, en el caso de una compañía transportadora donde uno de sus conductores provocó un trágico accidente, debido a que se quedó dormido al volante, porque la compañía lo obligó a conducir en jornadas que no tuvieron en cuenta las horas de descanso a que tiene derecho todo conductor (Hernández 2010), y así puede ocurrir con otro 
tipo de delitos como la falsedad en documento público, estafas, homicidios culposos, lesiones personales, entre otras.

De esta forma, en ambos casos a saber, cuando existe una organización criminal ocultándose debajo del velo corporativo de la sociedad o cuando la empresa en desarrollo de su objeto social infringe ocasionalmente la ley penal, se hace necesario tener claridad sobre la imputación que le corresponde a cada participante que intervino en el hecho, para no infringir las garantías constitucionales y legales que limitan la persecución penal.

El tema que vamos a tratar en este artículo es la autoría y la participación en la responsabilidad penal por el producto, esto es, quiénes son responsables y a título de qué se le podría imputar responsabilidad penal (autor o partícipe), cuando la empresa en desarrollo de su actividad comercial produce, distribuye y vende al público, un producto que por padecer de un defecto o por contener sustancias nocivas para la salud, pueden lesionar bienes jurídicos como la vida y la integridad personal.

\section{PLANTEAMIENTO DEL PROBLEMA}

Por regla general, la responsabilidad penal del producto se presenta a título de culpa o imprudencia, es decir, el actor no tiene la intención al momento de producir, distribuir o vender un producto al público, de lesionar bienes jurídicos tutelados por el derecho penal. Sin embargo, como veremos a continuación en uno de los casos más emblemáticos de la responsabilidad por el producto, la modalidad de la conducta, podrá transformarse en dolosa, si el autor después de un tiempo termina conociendo los defectos que tiene el producto y los efectos que puede ocasionar a sus consumidores, y aún así no hace nada para evitarlos.

El tema de la responsabilidad penal por el producto, puede producir todo un universo de posibilidades en la casuística, porque de acuerdo con las circunstancias en que se desarrollen los hechos puede variar la imputación penal, ya sea desde la modalidad de la conducta, esto es dolo o culpa, o desde la autoría y la participación. Con lo anterior encontramos unas complejidades dogmáticas muy relevantes, porque dependiendo de la modalidad de la conducta que se configure en cada caso, se pueden proponer otro tipo de debates en el campo de la autoría y la participación. Así por ejemplo, si la modalidad es dolosa, habrá que analizar quiénes actúan como coautores, determinadores y cómplices. En cambio, si la modalidad es culposa, la discusión se concentra en quiénes son o no son autores.

Lo anterior se debe a una discusión no muy pacífica en la doctrina, donde la posición mayoritaria (Cuello, 2009) considera que la distinción entre autor y partícipe solo se presenta en los delitos dolosos, más no así en los delitos culposos, en los que todo aquel que aporte una causa al resultado es autor. Otro sector minoritario (Feijo, 2007) en cambio, considera que el concepto restrictivo de autor, es decir que distingue entre autores y participes, debe ser aplicado tanto en delitos dolosos como en delitos culposos, porque así lo establece la Ley penal (artículo 28 del Código Penal Colombiano) al hablar de autores y participes ${ }^{1}$.

Por la extensión de este trabajo y por la dificultad del tema, no es posible agotar esta discusión, así que el planteamiento se limita a algunas discusiones y posturas sobre el tema.

Para iniciar el análisis de este artículo, conviene hacer un pequeño resumen sobre el caso de Lederspray ocurrido en Alemania en la década de los 80's, que sin duda es uno de los casos más emblemáticos sobre la responsabilidad penal por el producto.

Todos estos temas, se analizaran desde los criterios de responsabilidad penal dados por la doctrina

1 Artículo 28 del Código Penal colombiano: Concurso de personas en la conducta punible. Concurren en la realización de la conducta punible los autores y los partícipes. 
y dentro de los cánones legales de la Legislación penal colombiana.

\section{CASO LEDERSPRAY}

Este caso ocurrió en Alemania, donde la empresa Werner und Mertz BmbH fabricaba un aerosol destinado al cuidado de zapatos y otros artículos de cuero. El producto era comercializado a través de dos empresas (E.R. GmbH y S-GmbH) que hacían parte de un mismo grupo económico denominado E.R. GmbH. A mediados de 1980 la empresa comenzó a recibir informes de personas que habían utilizado el producto y que venían sufriendo de ciertas molestias de salud, como trastornos respiratorios, tos, náuseas, escalofríos y fiebre, y también se relacionó con casos de edema de pulmón.

Los informes motivaron a la empresa en la realización de varios estudios con fundamento en los embases que devolvían los clientes, en ellos, no se hallaron defectos de fabricación, pero si se encontró modificación en la composición del producto, pues se había elevado la proporción de aceite de siliconas. A pesar de ello seguían llegando más informes de personas afectadas, por esto la empresa consultó a médicos y toxicólogos de dos compañías químicas, pero tampoco se logró encontrar ningún problema en los componentes del producto. También se cambiaron los proveedores de ciertas materias primas, volviendo a los proveedores de la fórmula inicial, con el objeto de eliminar las contrariedades presentadas con los usuarios.

En 1981, se encontró que ahora los problemas no solo provenían de una de las marcas de aerosoles de la compañía, sino de dos marcas, por lo que a mediados de abril de 1981 se decidió suspender por un corto tiempo la producción y la comercialización de ambos productos. Pero luego de un nuevo estudio de la división química de la empresa, donde tampoco se encontró la razón de los problemas, se decidió continuar con la producción y la distribución.
El 12 de mayo de 1981, se reúne la dirección de las tres empresas incluida entre ellas la matriz del grupo, para tocar el tema de los casos conocidos de trastornos padecidos por los usuarios. En esa reunión participó el responsable del laboratorio central de la firma, quién presentó su informe exponiendo que después de los estudios realizados no se había detectado ninguna sustancia tóxica al producto, por lo que se descartaba su peligrosidad y por ello no era necesario retirarlo del mercado. En dicha reunión también se ordenó realizar nuevos estudios y se acordó también colocar una etiqueta al producto donde se les anunciaran a los consumidores que el producto estaba bajo estudio, en caso que las investigaciones arrojaran como resultado "un auténtico defecto del producto" o "un riesgo comprobable derivado de su uso".

En Septiembre de 1983 la Oficina Federal de la Salud y el Ministerio de la Juventud, la Familia y la Salud alemanes, intervinieron la empresa Werner und Mertz, y ésta decidió retirar el producto del mercado.

Los hechos anteriormente resumidos, dieron lugar a una sentencia del Tribunal Supremo de Alemania, donde se destacan dos problemas centrales:

El primero consistió en que luego de varios estudios científicos no se logró establecer en el juicio, si el producto contenía alguna sustancia tóxica. El Tribunal alemán concluyó que el juicio de responsabilidad penal no tiene como finalidad demostrar científicamente cual era la sustancia tóxica que contenía el producto, sino que era suficiente con verificar la relación causal entre la afectación a la salud de los consumidores, con el consumo del producto, llegando a descartarse cualquier otra causa como origen de los cuadros clínicos padecidos.

El segundo problema, consistió en construir la posición de garantes de los empresarios para imputarles responsabilidad penal. Para ello se fundamentó la responsabilidad penal por comisión 
por omisión, por no realizar la acción prudente de retirar los productos del mercado o de advertir a los usuarios de los peligros de su utilización. La posición de garante, que se les configuró, fue el tener bajo su cargo la vigilancia de una fuente de riesgo, en este caso, la producción y comercialización de un producto peligroso. Sin embargo, el tribunal dividió los hechos de acuerdo con el tiempo, para establecer las siguientes responsabilidades:

1. Los primeros casos presentados, antes de la llegada de los primeros informes sobre los daños que ocasionaba el producto, fueron considerados por el Tribunal Supremo Alemán como casos fortuitos, de acuerdo al estado de la ciencia en el momento de la producción, los daños ocasionados por el producto no le eran previsibles al fabricante.

2. Luego de la llegada de los informes de los primeros casos y hasta la reunión del consejo directivo del grupo empresarial, las lesiones personales fueron imputadas como una omisión impropia a título de imprudencia, al considerar como imprudente la omisión de no retirar el producto del mercado y permitir que se siguiera utilizando.

3. Luego de la reunión del grupo directivo, ante la acumulación de evidencia sobre los efectos nocivos del producto y la persistencia en no retirarlo del mercado, los nuevos hechos presentados a partir de esa fecha, se imputaron como una comisión por omisión a título de dolo eventual.

4. Por último, la decisión de producir y comercializar más cantidades de aerosol en el mercado, fue imputada como lesiones personales dolosas por acción.

Este caso, permite iniciar el análisis dogmático sobre la responsabilidad penal por el producto, pues si bien puede ser claro el concepto de imputación en los momentos referidos por el Tribunal Supremo Alemán, existen ciertos aspectos que se hace necesario aclarar.

\subsection{La posición de garante}

De conformidad con la legislación penal colombiana, la posición de garante se puede configurar tanto en la modalidad dolosa, como en la modalidad culposa, pues la ley no expone limitación alguna. El artículo 25 del C.P. no hace ninguna distinción y se entiende que la posición de garantía, se configura no por la modalidad de la conducta, sino por tener a su cargo la protección de un bien jurídico o la vigilancia de una fuente de riesgo (lo anterior cuando se configura alguna de las posiciones de garante que son la asunción voluntaria, la estrecha comunidad de vida, el inicio de una actividad riesgosa o la creación del riesgo precedente) y la responsabilidad se configura, al no realizar las acciones necesarias para impedir los resultados contenidos en un tipo legal, sin importar que la omisión sea dolosa o culposa.

Sobre el tema, se manejan varios planteamientos para dotar de contenido a la posición de garante, por una parte se encuentra la teoría del profesor Roxin en relación con los delitos de infracción a deber (Roxín, 2007, pp. 385-393), según la cual, existen delitos en los que no se aplica la teoría del dominio del hecho, sino que se analiza si el autor tenía bajo su cargo el cumplimiento de ciertos deberes establecidos en normas extrapenales, dirigidos exclusivamente al autor para la protección del bien jurídico en el caso concreto. La infracción de esos deberes legales, configura la responsabilidad penal, sí por su incumplimiento se vulneró un bien jurídico. Esa teoría a su vez, adiciona otro elemento y es que con la infracción a ese deber, debe aumentarse el riesgo a niveles intolerables por encima del riesgo permitido.

La aplicación de esta teoría se encuentra presente en la decisión del Tribunal Supremo Alemán, que fundamentó la condena por lesiones personales imprudentes, porque la Ley alemana establecía la obligación del productor de retirar el producto cuando este, representara un peligro para salud humana (Sarrbayrrouse, pp. 58-63). Así mismo, consideró de temerario el hecho de mantener el producto en el mercado, muy a pesar de las 
evidencias que señalaban que el producto sí estaba causando un daño los consumidores. En términos del profesor Roxin, los empresarios infringieron un deber establecido una norma extralegal, con lo cual aumentaron el riesgo de lesión al bien jurídico por encima del riesgo permitido (Cadavid, 2005, pp. 75-81) y por lo tanto, son sancionables (Roxín, 2007, pp. 385-393).

Por otra parte, también está la tesis del profesor Jackobs (1998, pp. 73-101), quién plantea que todas las personas tienen el deber de organizar su vida de tal manera que no ocasione daños a las demás personas, de ahí se explica la omisión por dominio de la organización, que se plantea los deberes para todos los individuos de acuerdo con sus roles. Pero también explica, que existen ciertas personas que asumen ciertos deberes concretos, de evitar ciertos resultados de acuerdo con una función, cargo o posición en determinados contextos sociales, por lo cual, se dice que si la persona es competente para evitar cierto resultado de acuerdo con su rol especial, será responsable si no actúa y el resultado se produce, esto es denominado como el dominio sobre la institución. En el caso de Lederspray, de acuerdo con la teoría del profesor Jackobs, los empresarios eran competentes para evitar el resultado incumpliendo el deber socialmente esperado de evitar la lesión de los consumidores.

Otra postura sobre el tema la tiene el profesor Schunemann (2007), quien a diferencia de los autores antes citados, el derecho penal no puede depender de normas extrapenales para fundamentar la responsabilidad penal, ni tampoco de la competencia o de los roles sociales de un ciudadano y ello primero, porque el derecho penal debe ser independiente de otras áreas del derecho y debe ser capaz de imputar responsabilidad penal, aún cuando las normas extrapenales no existan o se contradigan (Schunemann, 2007, p. 206). Mientras que el criterio de la competencia o los roles sociales, constituyen un peligro para la seguridad jurídica que debe mantener el derecho penal e impiden la diferencia entre el autor y el partícipe, porque imputa responsabilidad a todos los que de acuerdo con los roles, se consideren competentes (Schunemann, 2007, pp. 202-203).

Por ello, considera que el fundamento de la responsabilidad penal por una omisión debe recaer sobre la evitabilidad del resultado, es decir, si la persona tiene el dominio sobre la protección de un bien jurídico o sobre la vigilancia de una fuente de riesgo, será responsable penalmente si previendo un resultado lesivo, dentro de su ámbito de dominio, deja que el curso causal continúe, como ocurre en el caso del dueño de un perro, quién viendo que el animal va a atacar a otra persona, no hace nada, pudiendo hacer algo (Schunemann, 2007, pp. 203-218), posición que compartimos en este trabajo.

De conformidad con esta última tesis, la responsabilidad de los directivos de Lederspray se debió fundar en su dominio sobre una fuente de riesgo que constituía un producto (Bacigalupo, 2004), de acuerdo con las evidencias conocidas, era muy seguro que estaba causando un daño y pudiendo evitarlo con alguna decisión (ámbito de dominio), dejaron que el curso causal continuara y se produjeran los resultados típicos.

\subsection{Principio de confianza y la delegación}

De acuerdo con el artículo 9 del Código Penal colombiano, "Para que la conducta sea punible se requiere que sea típica, antijurídica y culpable. La causalidad por sí sola no basta para la imputación jurídica del resultado." Esta referencia a la causalidad por sí sola, no basta para la imputación jurídica del resultado, permitiéndole a la doctrina y a la jurisprudencia plantear la aplicación de los criterios de la imputación objetiva, para limitar el ámbito de protección del derecho penal a sólo aquellos cursos causales más relevantes, de conformidad con los avances de la teoría de la imputación objetiva.

En el sector empresarial, la división de trabajo y la especialidad de las funciones son conceptos necesarios para el desarrollo de cualquier actividad comercial. En toda empresa existe una estructura de trabajo que se relaciona de 
manera horizontal, esto es, entre personas que desde una misma posición jerárquica coordinan determinada actividad y de manera vertical, que se presenta en las relaciones, donde unas personas se encuentran subordinadas a la autoridad de un funcionario de mayor jerarquía.

Esta realidad obliga a tener en cuenta el principio de confianza, que es uno de los criterios de la imputación objetiva especialmente aplicable a los trabajos en equipo. Este principio permite dinamizar el trabajo coordinado de varias personas, evitando el control sobre el control, porque se fundamenta en la confianza de los participantes en una labor, a cumplir con la parte que le corresponde (Roxín, 2004), o en palabras más técnicas, el principio de confianza predica que una persona puede confiar dentro del tráfico social y jurídico, en el cumplimiento por las demás personas a los deberes o funciones que le han sido asignadas (López, 1996, p. 112). De esta manera, se entiende que cada persona es responsable por la parte del trabajo asignado y si una yerra, esta se hace responsable y no afecta a los demás participantes.

Sin embargo, el principio de confianza no es absoluto, se aplica de una manera más amplia en las relaciones horizontales (que se dan entre coordinación entre personas de la misma posición laboral jerárquica), pero incluso en ellas, se limita en casos donde las personas en las que se tiene que confiar son inimputables o personas cuya condición física o psíquica evidencian que no van a cumplir con la norma de conducta. También se limita la aplicación del principio de confianza en relaciones horizontales, en aquellos casos donde es evidente que la persona asignada para ejecutar determinada labor, no va respetar o no está respetando la norma de conducta (Cesano, 2007).

En las relaciones verticales (que se dan en aquellas labores en las que varias personas se encuentran subordinadas a un superior jerárquico), el principio de confianza es aún más limitado, porque en estas, el superior conserva sobre el trabajo del subordinado deberes de control y vigilancia. En estos casos, estos deberes de control y vigilancia pueden aumentar o disminuir de acuerdo a la experiencia y conocimientos del subordinado, así por ejemplo, el grado de vigilancia y control sobre un aprendiz es mucho mayor al que se debe ejercer sobre un técnico con 10 años de experiencia.

Otra limitación a la aplicación del principio de confianza, se presenta cuando existe una posición de garante ${ }^{2}$ en una o en varias personas que participan en la actividad, como por ejemplo: de determinado trabajo en una construcción participan obreros, ingenieros, directores y supervisores al tiempo, donde tanto los ingenieros, directores y supervisores tienen posición de garante y por tanto dentro de su ámbito de dominio, deben realizar todas las acciones pertinentes, para evitar los daños previsibles que se puedan presentar.

Volviendo al tema empresarial, autores como Meini, Cervini y Adriasola, consideran que el funcionamiento de una empresa o de una actividad comercial tiene ciertos riesgos inherentes a su normal desarrollo, los cuales deben ser mantenidos por toda la estructura empresarial encabezada por los dueños, dentro del riesgo permitido, para no causar daños en el desarrollo de la actividad a los bienes jurídicos del resto de la sociedad (Adriasola, 2005, p. 255). Este planteamiento, permite configurar una posición de garante por el dominio sobre una fuente de riesgo, que es inherente al funcionamiento de

2 Se pueden desde ya establecer tres grupos de casos en los cuales se limita la aplicación del principio de confianza: 1) Cuando se puede inferir concretamente que el otro participante en el trabajo en equipo no va a cumplir con sus deberes; 2) frente a determinadas personas como niños, ancianos, inimputables, un ebrio o estados similares de cuya condición no se pueda esperar una conducta ajustada a su deber; y 3) cuando el deber de cuidado de una persona consiste en la vigilancia y control de otras personas que se encuentra bajo su mando. CESANO, José Daniel. Los delitos de homicidio y lesiones imprudentes por mala praxis médica. Tratado de responsabilidad médica. Legis argentina. 2007. Pág. 766; también sobre el tema CORCOY, Ob. Cit. Pág. 316 
la empresa o al desarrollo de una actividad comercial y por esta razón, se entiende limitada la aplicación del principio de confianza, por la posición de garantía que pesa sobre los empresarios.

Sin embargo, la posición de garante que tienen los empresarios se puede transmitir y redistribuir en toda la estructura empresarial. En la actualidad existe una distinción entre quienes detentan la propiedad de la empresa (socios) y quienes la administran (administradores o juntas directivas), por tanto, no siempre el que ostenta la calidad de propietario es quién toma las decisiones más importantes de la empresa, precisamente porque los propietarios delegan la función de administrar en los órganos de administración, que pueden ser gerentes, administradores o juntas directivas (Cesano, 2010, p. 187).

Así entonces, los dueños pueden delegar su posición de garante a los administradores o juntas directivas y éstos a su vez, pueden delegarla en supervisores, jefes de personal, jefes de departamentos y otros empleados y con ello, la posición de garantía sobre la evitabilidad de ciertos resultados típicos que se pueden producir en desarrollo de la actividad empresarial, queda repartido entre los diferentes miembros de la estructura de la organización, permitiendo volver a los efectos prácticos del principio de confianza, en relación con las actividades delegadas (Cervini, 2005, p. 247-255).

Precisamente, el acto de delegación se concreta y transmite en la posición de garantía, del delegante al delegatario cuando el primero suministra al segundo la información y los medios necesarios para cumplir eficientemente la función delegada. Sin embargo, en todo caso, el delegante seguirá siendo responsable por dos eventos: el primero, que mantiene su responsabilidad sobre el nombramiento, es decir si la persona que nombró es idónea para cumplir la función asignada y el segundo, que mantiene bajo su responsabilidad la obligación de controlar y vigilar el trabajo delegado de manera eficiente y periódica (Cervini, 2005, pp. 255-259).
Hechas las anteriores aclaraciones, Silva Sánchez considera que el delegante no puede responder como autor de un delito cometido por acción o por omisión del delegado, porque a pesar $\mathrm{de}$ que tiene las obligaciones de control y vigilancia sobre el trabajo del delegado, no tiene la posibilidad efectiva de evitar el resultado, en virtud de ello, debe responder como cómplice (Silva, 2001, p. 19).

En el caso de Lederspray, podría plantearse un problema sobre el tema de la delegación de las posiciones de garante. En primer término se aclara que quienes fueron sancionados fueron los directivos y no los socios, ello se debe al acto de delegación que ellos hicieron conforme al cual, las decisiones sobre la producción, comercialización y venta del producto las tomaban los miembros de la junta directiva, sin embargo, debido a la magnitud e importancia de los hechos, los socios debieron ejercer sus funciones de control y vigilancia que debieron ejercer en ese caso, por tanto, pudieron haber sido imputados por lo menos a título de cómplices de los casos reportados luego de la reunión de la junta directiva.

En segundo término, parece discutible la responsabilidad de los miembros de la junta directiva por los hechos ocurridos entre los informes recibidos de casos de usuarios afectados y la reunión de la misma donde se tomaron las decisiones, pues es posible plantear que la calidad y las condiciones del producto se encontraba en cabeza del departamento químico y de otros empleados de inferior jerarquía, por tanto, ellos no tenían el dominio directo sobre la fuente de riesgo. Además, los directivos ordenaron estudios tanto químicos, como médicos sin que con ello se encontrara la causa del problema. Igualmente suspendieron la producción y comercialización del producto por un tiempo. Con este conjunto de acciones preventivas, se puede afirmar que estaban ejerciendo su función de control y vigilancia sobre la fuente de riesgo.

Otro punto de controversia: la acusación se basa en la decisión que ha debido adoptar la junta directiva, por ser la más prudente, cual era retirar 
el producto del mercado, teniendo en cuenta los informes de casos reportados. Pero por la otra, se puede argüir que la junta directiva no permaneció inactiva durante los hechos, siempre ejerció funciones de control y vigilancia sobre la fuente de riesgo y por ello iba adoptando paulatinamente decisiones de control y cuando se verificaban que las anteriores no tenían efecto, se tomaban unas nuevas. Igualmente, se puede argumentar que la empresa realizó todo lo posible para detectar las causas de las molestias sufridas por los consumidores, pero ello no fue posible, causas que no se demostraron ni siquiera por los estudios científicos realizados durante el juicio.

Por ello cabría preguntarse si ¿Era el retiro del producto la decisión más prudente que debían adoptar los miembros de la junta directiva? Si la respuesta es sí, debido a la gravedad de los síntomas de los consumidores, entonces por lo menos se debió degradar la culpa, de culpa grave a culpa leve en los sistemas que establecen la graduación de la culpa como el español o en su defecto debió disminuirse la culpabilidad y con ello la pena en el sistema de cuartas punitivas como en el sistema colombiano (artículos 60 y 61 del Código Penal Colombiano), porque en el caso planteado si existe evidencia del ejercicio del control y de la vigilancia sobre la fuente del riesgo, otra cosa es considerar que debió ser otra la decisión más prudente.

En tercer término, se presenta un problema de error, los directivos no tienen la obligación de ser científicos para ejercer su cargo, por tanto, delegaron los estudios en el personal calificado de la empresa y luego confiaron en los resultados arrojados por dichos estudios, pues de hecho, de acuerdo con los resultados de las pruebas químicas y médicas realizadas por la empresa, los miembros de la junta podrían haber actuado bajo un error vencible al convencerse, de acuerdo con los resultados de los estudios, que el producto no generaba ningún peligro para la salud humana (Artículo 32 numeral 10 del Código Penal). Y por otra parte, frente a un error de prohibición vencible sobre la elección de la mejor decisión a adoptar, como si se trataré de una colisión de deberes (artículo 32 numeral 11 del Código Penal) ${ }^{3}$.

Por lo anterior, el error de tipo ${ }^{4}$ pudo haber anulado la posibilidad de imputarles la omisión a título de dolo eventual, por no haber suspendido la comercialización del producto y el dolo por acción por haber ordenado mayor producción, debido a que ambas decisiones se basaron en estudios científicos que los indujeron a error. Y el error de prohibición pudo haber disminuido la pena a la mitad, tanto en las lesiones imprudentes, como en las lesiones dolosas, debido a la toma de una decisión errada, luego de presentarse en el debate una colisión de deberes, teniendo siempre presente que se realizaron estudios científicos que no daban con las causas de los padecimiento de los usuarios. Ahora, en este caso, es posible proponer la aplicación de ambos errores, logrando a través del error de tipo eliminar el dolo, dejando subsistente la conducta imprudente (artículo 32 numeral 10 del C.P.) y a través del error de prohibición, disminuir la culpabilidad a la mitad (artículo 32 numeral 11 del C.P.) (Abello, 2008, pp. 100-109).

3 "Ahora bien, las anteriores manifestaciones del elemento cognoscitivo deben ser cuidadosamente distinguidas de la posibilidad de conocer el deber de cuidado que, como conocimiento potencial de la antijuridicidad, es un verdadero problema de culpabilidad, y el error que sobre ella recaiga es de prohibición." VELASQUEZ VELASQUEZ, FERNANDO. Manual de Derecho Penal parte General. Comlibros. 2007. Pág. 334; El profesor GOMEZ PAVAJEAU al trabajar las conductas de omisión considera que los errores sobre las posiciones de garante que impliquen una valoración son errores de prohibición. GOMEZ PAVAJEAU, Carlos Arturo. Estudios de dogmática en el nuevo código penal. Primera parte. Segunda edición. Ediciones jurídicas Gustavo Ibáñez.2003. pág.342

4 Sobre el tema VELASQUEZ VELASQUEZ, Fernando. Manual de derecho penal. Ob. Cit. Pág. 299; TORRES VASQUEZ, Filemón El error en el derecho penal colombiano. Monografías módulo penal No.9. Editorial Ibáñez. Universidad Santo Tomás.2007. Pág. 127-128; FERNANDEZ CARRASQUILLA, Juan. Delito y error. Segunda edición. Leyer. 2007. Pág.166; GOMEZ PAVAJEAU, Carlos Arturo. Estudios de dogmática en el nuevo código penal. Op. Cit. pág. 342 
Ahora, es de aclarar que la aplicación absoluta del principio de confianza a los directivos, respecto de los estudios científicos realizados por los químicos de la compañía, no era posible, porque los informes de los casos reportados de usuarios afectados evidenciaban, que a pesar de los resultados de los estudios realizados por la empresa, se podía preveer que algo extraño sí estaba pasando con el producto y ello no era explicable científicamente.

\subsection{Autoría y participación en las conductas dolosas}

Como se planteó en el resumen del caso Lederspray, el Tribunal Supremo alemán condenó a los directivos, en calidad de autores por lesiones personales culposas por omisión, por los hechos ocurridos desde el inicio de los informes de casos hasta antes de la reunión de la junta directiva; por lesiones personales dolosas por omisión, por no haber retirado el producto del mercado, luego de la reunión de la junta directiva y por lesiones personales dolosas por acción, por dar la orden de continuar con la producción.

De acuerdo con los hechos, tendríamos que analizar el tema de la autoría y la participación en las tres imputaciones realizadas por el alto Tribunal Germano. Para comenzar, se debe analizar la responsabilidad penal dentro de la estructura empresarial desde arriba hacia abajo $y$ viceversa.

Iniciaremos con el análisis de las lesiones personales dolosas por omisión, según el Tribunal los directivos incurrieron en dolo eventual, al no tomar la decisión de retirar el producto del mercado, dejando que las lesiones personales se produjeran al azar. Para el alto Tribunal, a pesar de que la decisión de retirar el producto debía tomarse por parte de todos los miembros de la junta directiva, cada uno individualmente tenía una posición de garante como fabricante y debía hacer todo lo posible y exigible, para que se llevara adelante la decisión de retirar el producto del mercado, a pesar de que su voto no fuera suficiente para que se tomara la decisión colectiva, su deber era decidir a favor del retiro del producto (Sarrbayrouse, 2004, pp. 62-63).

También fueron imputados como coautores, los miembros de las filiales que no asistieron a la reunión -pues la decisión se tomó en la junta directiva de la empresa matriz-, pero que igual recibieron suficiente información sobre la decisión tomada, la aprobaron y la asumieron en los ámbitos de su responsabilidad, que era la comercialización del producto. Para el Tribunal no era necesario un compromiso previo, sino que era suficiente un acuerdo producido durante el desarrollo del hecho (Sarrbayrouse, 2004, p. 62).

Por su parte, el director del laboratorio de la empresa, quién presentó el informe el día de la reunión y afirmó de acuerdo con el estudio realizado, la composición y las propiedades no tóxicas del producto, su carencia de peligrosidad y propuso realizar un nuevo estudio e informar a los usuarios sobre ello, fue considerado por el Tribunal de primera instancia como cómplice, porque informó y aconsejó insuficientemente a los directivos para la toma de la decisión asumida, en la reunión del 12 de mayo de 1981 (Sarrbayrouse, 2004, p. 55).

Sobre las anteriores imputaciones debe hacerse un análisis más detallado. En primer término, la posición de garante de los miembros del directorio de la empresa en el caso Lederspray y su dominio sobre la evitabilidad del resultado -en términos de Schunemann, entendido este como el dominio sobre la vigilancia de una fuente de riesgo-, se concreta porque ellos podían tomar la decisión de retirar el producto del mercado y con ello evitar las lesiones personales a los consumidores. En consecuencia, se puede aceptar la coautoría de todos los miembros de la junta que no tomaron la decisión de retirar el producto, teniendo presentes las consideraciones expresadas en el aparte anterior sobre el error de tipo y error de prohibición en que pudieron incurrir al tomar la decisión, tomando como base la legislación penal colombiana. 
Sobre este tópico, el considerar como cómplice al jefe del laboratorio de la empresa podría considerarse como decisión muy discutible, partiendo de la legislación penal colombiana, porque fue su informe la base de la decisión de la junta directiva. En tal sentido, que no podría afirmarse que sea un aporte al hecho de un tercero (artículo 30 inciso 3 del C.P.), sino prácticamente una instigación o determinación (artículo 30 inciso 2 del C.P.) a adoptar una decisión que configuró la responsabilidad penal dolosa por omisión y por acción de los directivos. Bien se podría haber argumentado que el informe fue un factor que influyó en un error de tipo y de prohibición vencibles de los directivos al tomar la decisión, máxime si se tienen en cuenta los resultados y las recomendaciones del informe.

Ahora, ello tiene unos efectos en la determinación de una posible autoría en el jefe del laboratorio, pues su responsabilidad como instigador de un delito doloso, podría variar a autor mediato, al aprovecharse del error vencible de los miembros del cuerpo directivo (artículo 29 inciso 1 del C.P.). Sin embargo, no parece convincente que el jefe del laboratorio de acuerdo con los resultados arrojados por su propio estudio, actuara de manera dolosa para engañar a los directivos y convencerlos de realizar su propio delito. Además, el caso tiene una complejidad porque ni con los estudios realizados dentro de los laboratorios de la empresa, ni con los otros realizados durante el transcurso del proceso, pudieron explicar las causas que vinculaban al producto con las enfermedades que padecían los consumidores. Sin embargo, es posible imputarle cargos como autor culposo, en tanto que su conducta de recomendar la comercialización del producto podía constituirse como una conducta culposa, por omisión al deber objetivo de cuidado, y con ello permitir la ocurrencia de un resultado previsible que confió en poder evitar (artículo 23 del C.P.).

Estos hechos no pueden configurar un dolo directo, pero quedan en la frágil frontera entre el dolo eventual y la culpa con representación. El
Tribunal alemán se decidió por el dolo eventual en el caso de la omisión dolosa, porque a pesar de los informes que relacionaban el producto con las patologías sufridas por los consumidores, la empresa decidió continuar con la comercialización del mismo, esto se adapta más a la definición del dolo eventual, pues es como si los miembros directivos de la empresa previeran la producción de un resultado típico y su realización la hubiesen dejado librada al azar. A pesar que la empresa ordenó nuevos estudios e informó a los consumidores sobre la situación, así como del posible retiro del producto, dichas acciones no se podrían interpretar como conductas evasivas que evitaran o disminuyeran la posibilidad de ocurrencia del resultado, por lo que no permitiría la configuración de la culpa con representación.

Sin embargo, la pregunta que surge es si los informes sobre la persistencia de patologías en los consumidores a pesar de haber cambiado proveedores y haber revisado la composición del producto un par de ocasiones, pudieron haberle restado tal credibilidad al informe del laboratorio, lo que pudiera transformar una culpa con representación (artículo 23 C.P.) en un dolo eventual (artículo 22 del C.P.), por la omisión de no sacar el producto del mercado. En el caso del aceite de Colza en España, el Tribunal español, también decidió condenar a los empresarios que distribuían el aceite de Colza, a pesar de que científicamente no se comprobó la relación de causa y efecto entre los componentes del aceite y las lesiones sufridas por los usuarios ${ }^{5}$. En estos casos se aplican los principios de precaución y pro hombre, según el cual, el juez debe decidir siempre de la forma que más se protejan los derechos humanos, por tanto, ante la posibilidad de daño a la salud humana por un producto, la obligación es la prohibición.

En el caso de la imputación de lesiones personales a título de acción, por haber ordenado mayor producción del producto, calificado por el Tribunal

5 Tribunal Supremo de España, en su Sentencia de 23 de abril de 1992. 
Supremo Alemán como doloso, consideró como coautores a los directivos de la junta, por tomar la decisión y también como coautores a los directivos de las filiales por ejecutar la decisión, a pesar de haber tenido acceso a la información que motivó la junta.

Sobre el tema, el profesor Meini tiene una posición diferente, pues diferencia la imputación en dos supuestos. El primer supuesto se presenta cuando los encargados de tomar una decisión antijurídica son los mismos que la ejecutan, en estos casos se configura la coautoría (Meini, 2005, pp. 242-247). El segundo supuesto se presenta cuando se aprueba un acuerdo antijurídico por un órgano directivo, pero la ejecución del mismo le compete a otras personas, en estos casos son autores quienes deben ejecutar el acuerdo, porque son ellos los que tienen el dominio del hecho y son cómplices necesarios (de acuerdo con la legislación española) los que aprueban el acuerdo antijurídico, pues sin éste no se puede ejecutar el acto antijurídico (Meini, 2005, pp. 247-251).

En la Legislación penal colombiana no existe la figura del cómplice necesario, por lo que la solución sería diferente, por tanto, solo quedarían las opciones de instigación o autoría mediata. En el primer caso, si se concibe que al tomar la decisión de continuar la producción, los directivos solo estén realizando un acto ejecutivo pero no dominan el hecho, por tanto, las deliberaciones presentadas en el acuerdo se pueden tomar como una instigación a un delito (artículo 30 inciso 2 C.P.), frente a los que van a ejecutar el acuerdo, en este caso, sería discutible imputar complicidad (artículo 30 inciso 3 del C.P.) al considerar que la aprobación de un acuerdo sea un mero aporte a la realización del acto, pues en el acto pueden encontrarse consideraciones y sobre todo una decisión que se traduce en una orden, por la cual, los subalternos deberán ejecutar el acto. $\mathrm{O}$ en el segundo caso, es decir la autoría mediata (artículo 29 C.P.) se presenta cuando utilizan a los ejecutores como medios o instrumentos para realizar su delito, en estos casos, el instrumento de acuerdo con la teoría tradicional de la autoría mediata debe actuar guiado por un error, o ser coaccionado con perder su empleo ${ }^{6}$.

Existe una tercera posibilidad que viene debatiéndose en la doctrina en el campo de la delincuencia empresarial y es posible aplicando la autoría mediata por dominio de la organización creada por Roxin. Por una parte, autores como Faraldo Cavana(1996) consideran que no se cumplen los requisitos de la autoría mediata por dominio de la organización (organización jerarquizada, intercambiabilidad del ejecutante, y operar al margen de la Ley) porque las empresas no pueden entenderse como organizaciones al margen de la Ley, de donde se desprende la predisposición de los ejecutantes a realizar delitos, supuesto que no se presenta en las empresas legales, donde los ejecutantes pueden negarse a la ejecución de la orden y denunciarla. Pero otros como Aramburo (2005) consideran que si es posible, pues en una empresa se puede encontrar una organización jerarquizada, donde el ejecutor puede ser intercambiable y el elemento de la predisposición a realizar los delitos se puede suplir con la subordinación de los ejecutantes en una empresa.

De aceptarse esta última posición, que no deja de causar fuertes resistencias en la doctrina, responderían como autores mediatos por dominio de la organización los directivos de la empresa por tener dominio sobre la organización empresarial y responderán los ejecutores como coautores por tener dominio sobre el hecho típico.

A esta última postura habría de criticarse para el caso colombiano, por concebir como autores o coautores a quienes no tienen dominio del hecho, vulnerando el principio del acto, que por una parte establece la necesidad de tener como más graves los actos de quién ejecuta la

6 “... en diversas ocasiones podrá valorarse como circunstancia que exonere o atenúe la responsabilidad penal del ejecutor, el que frente a la posibilidad de verse privado de su puesto de trabajo en tanto la directiva proviene de un estamento jerárquicamente superior al que éste ocupa en la empresa." MEINI, Iván. Op. Cit. pág. 250. 
conducta punible, de quién instiga o contribuye a la realización de la misma (Velásquez, 2010, p. 62). Por otro lado, el principio de culpabilidad también establece mayor culpabilidad en aquellos quienes ejecutan el acto, que quienes contribuyen o instigan (Velásquez, 2010, pp. 74-75). Desde el punto de vista punitivo, el Código Penal Colombiano estipula que el instigador y el autor tienen la misma pena (artículo 30 del C.P.), por tanto, no se justifica realizar una excepción al criterio del dominio del hecho -que es el criterio más aceptado para diferenciar a un autor de un partícipe-cuando no tiene ninguna diferencia de origen práctico en la punibilidad.

\subsection{Autoría y participación en las conductas imprudentes}

En todo caso, si se hubiese admitido la responsabilidad de los miembros de la junta directiva en la modalidad culposa, se presentaría la discusión sobre la coautoría imprudente y la determinación de un hecho culposo. Como se dijo al principio de esta exposición, la mayor parte de la doctrina no admite la participación en el delito imprudente, por considerar que la teoría del dominio del hecho que permite diferenciar entre el autor y el participe, no es aplicable en el delito imprudente, por ello, consideran como autor a toda persona que contribuya causalmente con el resultado imprudente, siempre que incurra en una infracción al deber objetivo de cuidado y ésta se concrete en el resultado típico previsible.

De acuerdo con esta teoría, sería autor el jefe del laboratorio por haber aconsejado a la junta directiva seguir con la producción y distribución del producto, a pesar de toda la evidencia que apuntaba a que éste estaba produciendo los daños en la salud. Por ello respondería como autor de lesiones personales imprudentes, porque infringió el deber objetivo de cuidado y se produjeron los resultados que eran previsibles.

Son autores accesorios cada uno de los directivos, porque cada uno de ellos con su decisión individual infringió el deber objetivo de cuidado y produjo un resultado que era previsible.
Pero también sería responsable toda persona que tuviera que ejecutar el acuerdo tomado por la junta directiva de la matriz, entre ellos los directivos de las filiales que continuaron con la comercialización de los aerosoles, los empleados que teniendo acceso a la información tuviesen que implementar las labores de producción y distribución del producto, a menos que actuaran bajo un error de tipo invencible.

La crítica que se realiza a esta solución, es que amplía el espectro de punibilidad, pues considera que todo aquel que aporte una causa al resultado podrá ser considerado como autor de la conducta imprudente, siempre que infrinja el deber objetivo de cuidado y éste se concrete en un resultado previsible. Una parte por ahora minoritaria de la doctrina considera que ello vulnera la distinción que establece el legislador entre autor y partícipe, al considerar que la mencionada distinción no solo opera en los delitos dolosos, sino también en los delitos culposos (Feijo, 2007).

La mayor parte de la doctrina considera que no es posible hacer distinción entre autor y partícipe en el delito imprudente, porque la teoría del dominio del hecho requiere de un actuar final, es decir, que el autor debe actuar con una finalidad y ello implica necesariamente el dolo sobre el resultado. Pero la posición contraria, considera, que no es proporcional que en el delito doloso se prevea una rebaja para el cómplice, mientras en el delito imprudente quién contribuye en la realización del resultado típico se le imponga la misma pena del autor.

En virtud de ello, se han planteado varias tesis sobre criterios que permiten diferenciar a los autores de los partícipes en los delitos imprudentes sobre los cuales quiero mencionar dos.

El primero es el criterio de la dominabilidad del hecho (Díaz y García, 1991: 627-629; Roso 2004:538) (Díaz y García, 1991, pp. 627-629), esta teoría contempla que la parte objetiva del tipo es igual tanto en delitos dolosos como en delitos imprudentes, por lo cual, tanto en unos, como en otros se debe distinguir entre autores y partícipes 
atendiendo el concepto limitado de autor (Roxin, 2007: 703-754) ${ }^{7}$. El criterio de la dominabilidad del hecho consiste en que es coautor de un delito imprudente aquel que mediando acuerdo común previo o concomitante y actuando con división de trabajo, domine el hecho extratípico con el cual se infringe el deber objetivo de cuidado, y además sea consciente que su conducta está vulnerando el deber objetivo de cuidado en ese caso. En consecuencia sería partícipe aquel que no tenga la dominabilidad del hecho extratipico. Esta teoría solo podría ser utilizada en la imprudencia consciente o la culpa con representación, porque requiere que el autor sea reflexivo respecto de su conducta extratípica, como constitutiva de una infracción al deber objetivo de cuidado.

7 El concepto limitado o restringido de autor, es aquel que diferencia entre y partícipes, partiendo de criterios valorativos que permiten fundamentar una diferencia entre las actuaciones de unos y otros, y en consecuencia proponer una diferencia punitiva. En la actualidad, el criterio mayormente aceptado es el dominio del hecho, pero también se han creado otros criterios valorativos como son el dominio del hecho funcional, el dominio de la voluntad, los delitos de infracción al deber -todos estos desarrollados por ROXIN, Claus. Autoría y dominio del hecho en el derecho penal. Sétima edición. Marcial Pons. 2007. Págs. 703-754-, los delitos de dominio sobre el resultado, la pertenencia del hecho, el dominio objetivo y subjetivo del hecho -temas que serán tratados con mayor detenimiento en otros apartes de este trabajo-, como los más relevantes. Sobre el tema consultar entre otros a: DIAZ Y GARCIA CONLLEDO, La autoría en el derecho penal. PPU. 1991. Pág. 42; FERNANDEZ BAUTISTA, Silvia. El administrador de hecho y derecho. Tirant monografías No. 519. Tirant lo Blanch. 2007. Págs. 69-77; SUAREZ SANCHEZ, Alberto. Ob. Cit. Pág. 129; QUINTERO OLIVARES, Gonzalo. Parte General del Derecho Penal. Segunda edición. Thomson aranzadi. 2007. Págs. 612-620; VELASQUEZ VELASQUEZ, Fernando. Derecho Penal parte general. Cuarta edición. Comlibros. 2007. Págs. 874-882; MIR PUIG. Santiago. Derecho penal parte general. Quinta edición.Tec foto. 2003. Págs.363-372; GIMBERNAT ORDEIG, Enrique. Autor y cómplice en derecho penal. BdF. 2007.págs. 3-38; BACIGALUPO, Enrique. Derecho Penal parte general. Ara editores. 2004. Págs.459-471; ROXIN, Claus. Autoría y dominio del hecho en el derecho penal. Marcial Pons. 2007. Págs. 53-79; JACKOBS, Gunther. Derecho penal parte general. Fundamentos y teoría de la imputación. Madrid: Marcial Pons - Ediciones jurídicas.1995. págs. 733-742; JESCHECK, HansHeinrich. Tratado de Derecho Penal parte general. Quinta edición. Comares. 2002. Págs. 697-699;
Lo anterior se puede explicar con el siguiente ejemplo, si dos obreros acuerdan tirar unos escombros contenidos en una carretilla que cargan ambos al tiempo, para arrojarlos de un tercer piso, donde era previsible que pudieran lesionar a alguien, a pesar de ello ambos miran y no ven a nadie, pero al arrojar los escombros matan a un transeúnte que pasa por el sector. En este caso ambos son coautores de homicidio culposo, porque ambos acuerdan realizar el hecho imprudente, dominan el hecho extratípico $y$ son conscientes de que su actuar omite el deber objetivo de cuidado. Sin embargo, si en el mismo caso existe un tercer obrero que les ayuda a llenar la carretilla con los escombros y que a pesar de saber del futuro accionar imprudente de sus compañeros, no carga junto con ellos la carretilla para arrojar los escombros desde el tercer piso, puede ser considerado como un cómplice de un delito imprudente, por carecer de la dominabilidad del hecho imprudente, es decir, cargar la carretilla y tirar los escombros a la calle desde un tercer piso.

La anterior doctrina podría justificar por ejemplo en el caso de Lederspray que el director del laboratorio a través del informe pueda ser considerado como cómplice si se considera que con la exposición del informe realizó un aporte al hecho imprudente, de avalar la decisión de no retirar el producto, porque el no tenía nunca la dominabilidad sobre ese hecho que causó lesiones personales imprudentes. Sin embargo, también se le podía considerar como instigador de un delito imprudente, si se entiende que convenció eficientemente a los directivos de no retirar el producto del mercado, como se mencionó en el aparte anterior; sin embargo, no se podrían considerar como autor, porque no tiene la dominabilidad del hecho imprudente, porque la decisión de retirar o no el producto del mercado se encontraba en cabeza de los directivos.

La otra solución que se puede presentar a la autoría y participación en los delitos imprudentes, es la delegación de Silva Sánchez (2004, p. 19) y que se explicó anteriormente. Según el autor 
citado, si una persona delega en otro la protección de un bien jurídico o la vigilancia de una fuente de riesgo, el delegante pierde el dominio sobre la evitabilidad del resultado típico, por lo cual, el delegado responde como autor y el delegante si omite la función de vigilancia y control responderá como cómplice.

Este criterio sirve para imputar responsabilidad penal como cómplices de las lesiones personales culposas a los socios de las compañías, en virtud de la delegación en la junta directiva de la empresa matriz, de retirar el producto del mercado; ellos en su función de vigilancia y control, como integrantes del máximo miembro rector de una sociedad, han podido también, evitar que el producto siguiera distribuyéndose en el mercado.

En el caso colombiano, la legislación penal en el artículo 28 establece que: "Concurren en la realización de la conducta punible los autores y los partícipes", en tal sentido, el intérprete siempre debe diferenciar quiénes son autores y quiénes son partícipes, cuando se presenta una conducta punible y a diferencia de la legislación alemana, que establece que los partícipes deben actuar de manera dolosa, la legislación colombiana no hace dicha distinción, por lo cual se abre la posibilidad de admitir la participación culposa en el delito culposo, a través de los criterios anteriormente mencionados. El tema central es establecer quién de los intervinientes tendría la dominabilidad del hecho en las conductas activas o la evitabilidad del hecho en las conductas omisivas, para luego señalar a los demás intervinientes como partícipes imprudentes en una conducta imprudente. Queda solo pendiente el tema, que si al admitir la participación en las conductas imprudentes en Colombia, éstas serían punibles o no, porque a diferencia de las conductas dolosas, las imprudentes solo son punibles cuando expresamente lo establece el legislador (artículo 21 del C.P.), es decir, en términos netamente legalistas, la participación imprudente solo sería punible si el legislador expresamente contempla tal posibilidad, sin embargo, también es posible interpretar la norma, en el entendido que el artículo $21 \mathrm{del}$
C.P. establece: "La culpa y la preterintención sólo son punibles en los casos expresamente señalados por la ley.", solo se refiere a la parte especial del Código, más no en los preceptos de la parte general.

\section{LA RESPONSABILIDAD PENAL POR EL PRODUCTO, UN CASO COLOMBIANO}

Los criterios que se acaban de esbozar para el caso Lederspray, pueden ser utilizados para casos colombianos de responsabilidad penal por el producto, así por ejemplo en el caso de la reconocida modelo Jessica Cediel ${ }^{8}$, que fue víctima de la aplicación de un tratamiento estético con el cual buscaba retocar sus glúteos. En este tratamiento, el médico tratante supuestamente inyectaría ácido hialurónico en los glúteos de la modelo, sin embargo, a pesar que la etiqueta describía la composición del producto y establecía que el contenido era de ácido hialurónico, realmente de conformidad con los estudios científicos realizados al producto utilizado por el médico estético, lo que contenía realmente era biopolímeros, es decir silicona líquida, que provoca problemas serios en la salud de los pacientes.

En este caso, la responsabilidad penal del médico depende a su vez de la responsabilidad penal por el producto, y en el cual se encuentran vinculados:

- El productor del medicamento defectuoso.

- Una entidad del Estado que es el INVIMA por otorgar el permiso de importación al producto defectuoso, en unas condiciones diferentes a la presentación del producto que se está distribuyendo en el país. Pues el permiso hace referencia a un producto que viene para suministrar en una cantidad específica

8 Los hechos de este caso han sido tomados de: Especiales Pirry "Riesgos y Peligros detrás de una cola perfecta; capítulos 1,2,3,4,5,6." Encontrado en la siguiente página web: http://www.youtube.com/watch?v=sVqONPAP39o consultado el día 10 de Diciembre de 2011. 
a través de inyecciones, por lo cual, contiene directamente las inyecciones.

- Una empresa importadora, que ingresa al país el producto y lo distribuye a las tiendas farmacéuticas.

- Las tiendas farmacéuticas que lo distribuyen al público, sin contraindicaciones.

- Los médicos que lo utilizan o consumen, en tratamientos para sus pacientes.

En este caso, se presentan dos irregularidades esenciales, la primera en las características de presentación del producto autorizado por el INVIMA para su importación, y su no correspondencia con las características del producto comercializado en Colombia, pues el permiso fue dado a un producto que viene en presentación con inyecciones y solo para ser inyectado en ciertas partes del rostro en pequeñas dosis, inferiores a las presentaciones que se están comercializando en el país. Y la segunda, que el producto que se está comercializando no tiene la composición que dice tener, porque en vez de ácido hialurónico, contiene biopolímeros.

Los delitos que se pueden configurar de acuerdo con los hechos son, las lesiones personales dolosas (arts. 111 a 116 C.P.) o culposas (art. 120 C.P.) atendiendo a los criterios que se explicarán a continuación. Igualmente las lesiones dependen también de los daños causados a las pacientes, porque estos pueden consistir en incapacidad para laborar (art. 111), deformidad temporal o transitoria (art. 113 C.P.), depende del caso, o perturbación funcional de órgano o miembro (art. 114 C.P.) de acuerdo también a cada caso, sin descartar que las lesiones producidas a los pacientes puedan generar la muerte, caso en el cual se configuraría un homicidio culposo o doloso en caso de configurarse el dolo eventual. Otro delito que se configura es el de corrupción de productos médicos (art. 372 C.P.), ya sea en la modalidad de alteración de producto médico que sería en el caso del productor o en la modalidad de comercialización, distribución o suministro, en el caso de la empresa importadora; las droguerías y los médicos que conocieran las irregularidades del producto. Esta conducta sólo podría aplicarse en los casos en que se demuestre el dolo, de acuerdo con los criterios que a continuación expondremos. Y por último, el hecho de distribuir, suministrar o comercializar, un producto sin el permiso del INVIMA, por lo menos en la presentación y para los fines otorgado en el permiso, es posible configurar el delito de Fabricación y comercialización de sustancias nocivas para la salud (art. 374 C.P.), delito que solo admite la modalidad dolosa y que solo sería posible imputar atendiendo a los siguientes criterios.

De acuerdo con lo anterior, las personas que desconozcan las dos anomalías presentadas por el producto y a su vez desconozcan los efectos adversos que producían en los pacientes, quedarían cobijados por el principio de confianza, y no responderían penalmente. En este primer caso, no se excluye de responsabilidad al productor, es decir, aquellas personas que conocen que la composición del producto no es la misma que aparece en la etiqueta del mismo, configurando su responsabilidad a título de dolo eventual.

Diferente situación se presentaría para las personas que conociendo alguna de las dos anomalías presentadas en el producto, porque el conocimiento de estos aspectos comprometería su responsabilidad a título de dolo eventual, no importa el lugar que ocupe en la cadena es decir producción, distribución o consumo del producto -en el caso del médico que es el que lo consume-.

Otra posibilidad se presenta, cuando las personas tienen la oportunidad de conocer los resultados adversos que tiene el producto en los pacientes y a pesar de no conocer alguna de las dos anomalías del mismo, continúan con su comercialización, distribución y consumo, configuraría una responsabilidad a título de dolo directo, porque en este caso, las personas conocen directamente de los pacientes y de los consumidores, que el procedimiento realizado produce efectos adversos en la salud y saben que no existe otra causa 
que los haya provocado (u otro curso causal que produzca el resultado típico). Este sería el caso de los médicos que conociendo los efectos perjudiciales del producto, siguen ofreciendo y practicando el tratamiento; también se incluyen en este campo, las farmacias y el importador, quienes habiendo sido informados por los usuario y por los médicos de los efectos nocivos del producto, continúan con su distribución.

En el caso del INVIMA, luego de reportados los primeros casos, ha debido iniciar las investigaciones correspondientes y en virtud del principio de precaución debió cancelar o revocar los permisos de importación y distribución del producto y si esta omisión se extendió en el tiempo a pesar de conocer el peligro que el producto representa para la salud humana, por existir una posición de garante de los funcionarios de esta entidad, derivadas de sus funciones públicas de velar por la salud pública, los funcionarios encargados de estos trámites, pueden ser acreedores de una imputación penal inicialmente a título de culpa y luego de transcurrido un tiempo sin que hayan actuado, a pesar de haber sido reportados varios casos similares, serían responsables a título de dolo eventual o dolo directo de una conducta omisiva, que consistiría en no revocar los permisos de importación y distribución del producto.

Desde el punto de vista de la responsabilidad penal empresarial, ya sea la empresa que produce, o la empresa que importa o comercializa el producto en Colombia, la responsabilidad penal comienza con aquellas personas encargadas de controlar la composición del producto y de verificar las condiciones de presentación del mismo en cada empresa. En igual sentido sus superiores inmediatos que tendrían las funciones de control y vigilancia sobre dicha función, precisamente al no controlar y vigilar el trabajo de sus subordinados. A la postre, se le podría imputar responsabilidad penal a cualquier miembro de la empresa que a pesar de conocer las anomalías del producto persisten en su producción, distribución o consumo, o que después de haber tenido la oportunidad de conocer las anomalías, no hubiesen hecho nada para informar de ello, a los gerentes de la empresa o a las mismas autoridades públicas; o que a pesar de haber conocido las anomalías del producto no hizo todo lo necesario para suspender su producción, distribución o consumo del mismo. Y por último, todos los miembros de la empresa que conociendo los efectos adversos que ha tenido el producto en los pacientes, no realice los actos necesarios para suspender o prohibir su producción, distribución, comercialización o consumo.

Todo lo anterior, teniendo presente lo antes dicho con relación al principio de confianza, el error de tipo, el error de prohibición y los criterios expuestos de autoría y participación en la responsabilidad por el producto, aunque a diferencia del caso de Lederspray, donde no se pudo comprobar científicamente el componente tóxico del aerosol, en este caso de biopolímeros si se ha comprobado científicamente los efectos adversos que este producto ocasiona en la salud humana, además que los médicos pueden evidenciar directamente como la causa de los daños en la salud de los pacientes: la aplicación de esta sustancia.

\section{CONCLUSIONES}

El fenómeno de la delincuencia empresarial viene cobrando una gran importancia dentro de las políticas criminales de los Estados, en virtud de la tendencia generalizada que plantea que la mayor parte de actividades comerciales sean desarrolladas por las empresas, y por ello la posibilidad que en desarrollo de sus actividades se pueda presentar un delito.

En las actividades criminales que se pueden presentar en desarrollo de actividades empresariales se consiguen encontrar tanto delitos dolosos como culposos, lo cual tiene trascendencia en la imputación de la responsabilidad penal a los miembros de la empresa.

Una de las formas de imputación que gana cada vez más campo en la responsabilidad penal empresarial es la posición de garante, según la 
cual, los empresarios tienen a su cargo el dominio sobre la vigilancia de una fuente de riesgo y por esto tienen la obligación de evitar los resultados que se puedan presentar en desarrollo del objeto social de la empresa, ya sea en la modalidad dolosa, como en la culposa, pues ésta figura como se estudio en este trabajo, es aplicable en estas dos modalidades de la conducta.

Otra forma de imputación muy debatida en la dogmática penal en los casos de la delincuencia empresarial es la autoría mediata por dominio de la organización, que como se discutió también en este trabajo, goza cada día de más adeptos, pero que sigue teniendo una fuerte resistencia en la dogmática penal por la vulneración de ciertas garantías penales como el principio del acto y por tener efectos imprácticos desde el punto de vista punitivo.

Por otra parte, los casos de delincuencia empresarial permiten abrir el debate sobre la necesidad de plantear criterios que permitan distinguir los autores de los partícipes de un delito imprudente y ello para buscar resultados más razonables.

\section{BIBLIOGRAFÍA}

ABELLO GUAL, Jorge Arturo. (2008). Estructura de la Responsabilidad Penal del Médico. Leyer.

ARAMBURO CALLE, Maximiliano Alberto. (2005). La delincuencia en la empresa: problemas de autoría y participación en delitos comunes. En Nuevo Foro Penal 68. Julio - Diciembre de 2005. Págs. 93-144

BACIGALUPO, Enrique. (2004). Derecho Penal parte general. Ara editores.

BACIGALUPO, Enrique. (2005). Posición de garante en el ejercicio de funciones de vigilancia en el ámbito empresarial. Curso de Derecho Penal Económico. Segunda Edición. Madrid: Marcial Pons, Ediciones jurídicas y sociales S.A.

BENITEZ ORTUZAR, Ignacio Francisco. (2008, Junio). La participación en el delito imprudente.
Distintas formas de abordar el alcance de la participación imprudente en hecho imprudente de otro constitutivo de delito. En la siguiente página web: http://vlex.com/vid/38656850 (Tomado el 11 de diciembre de 2011).

BUSTOS RAMIREZ, Juan y HORMAZABAL MALAREE, Hernán. (2006). Lecciones de derecho penal. Trota.

CADAVID QUINTERO, Alfonso. (2006). El incremento del riesgo como facto de atribución de resultados en la imprudencia. En Nuevo Foro Penal No. 67.Enero-Junio. Universidad Eafit.

CEREZO MIR, José. (2008). Derecho Penal parte general. Bdf.

CERVINI, Raúl; ADRIASOLA, Gabriel. (2005). Derecho penal de la empresa desde una visión garantista. B d F.

CESANO, José Daniel. (2007). Los delitos de homicidio y lesiones imprudentes por mala praxis médica. Tratado de responsabilidad médica. Legis argentina. 2007.

(2010). La imputación penal en el ámbito de la empresa y las estructuras omisivas: bases para su análisis. En Berruezo Rafael; Rodríguez Juan María; et al. Derecho Penal Económico. B d F.

CORCOY BIDALOSO, Mirentxu. (2008). El delito imprudente. Segunda edición. Colección Maestros del Derecho penal No 10. Bdf.

CUELLO CONTRERAS, Joaquín. (2009). El Derecho Penal Español parte general. Vol. II. Dikinson.

DEL CASTILLO CODES, Enrique. (2007). La imprudencia: autoría y participación. Monografías de Derecho Penal No. 10. Dykinson. Madrid.

DIAZY GARCIA CONLLEDO, (1991). La autoría en el derecho penal. PPU.

FEIJO SANCHEZ, Bernardo. (2007). Derecho penal de la empresa e imputación objetiva. Colección de derecho penal. Cámara de Madrid. 
FERNANDEZ CARRASQUILLA, Juan. (1998). Derecho penal fundamental vol. II. Segunda edición. Temis.

FERRE OLIVE, Juan Carlos; NUÑEZ PAZ, Miguel Angel; RAMIREZBARBOSA, Paula Andrea. (2010). Derecho Penal colombiano parte general. Ibáñez.

FEIJOO SANCHEZ, Bernardo. (2007). Derecho penal de la empresa e imputación objetiva. Cámara de Comercio de Madrid.

FEIJÓO SANCHEZ, Bernardo. (2003). Resultado lesivo e imprudencia. Universidad Externado de Colombia.

FEIJOOSANCHEZ, Bernardo. (2009). Cuestiones actuales de derecho penal económico. Bdf editores.

FIANDACA, Giovanni; MUSCO Enzo. (2006). Derecho Penal parte general. Temis.

FIGALGO Sonia, (2008) Responsabilidad Penal por ejercicio de la medicina en equipo. Coimbra Editora.

FERNANDEZ BAUTISTA, Silvia. (2007). El administrador de hecho y derecho. Tirant monografías No. 519. Tirant lo Blanch.

GIMBERNAT ORDEIG, Enrique. (2007). Autor y cómplice en derecho penal. BdF.

GOMEZ RIVERO, María del Carmen. (2003). La responsabilidad penal del médico. Tirant lo Blanch.

HERNANDEZ BASUALDO, Héctor. (2010). Apuntes sobre la responsabilidad peal imprudente de los directivos de empresa. En Berruezo Rafael; Rodríguez Juan María; et al. Derecho Penal Económico. B d F.

HERNANDEZ ESQUIVEL, Alberto. (2002). Autoría y participación. Lecciones de derecho penal parte general. Universidad Externado de Colombia.

JACKOBS, Gunther . (1995) Derecho penal parte general. Fundamentos y teoría de la imputación. Madrid: Marcial Pons - Ediciones jurídicas.
JAKOBS, Gunther. (1998). Imputación objetiva en el derecho penal. Universidad Externado de Colombia.

JARAMILLO, Carlos Ignacio. (2008). Responsabilidad Civil del médico. Civitas.

JESCHECK, Hans-Heinrich. (2002). Tratado de Derecho Penal parte general. Quinta edición. Comares.

LOPEZ DIAZ, Claudia. (1996). Introducción a la imputación objetiva. Universidad Externado de Colombia. Bogotá.

MEINI, Iván. (2003). Responsabilidad penal del empresario por los hechos cometidos por sus subordinados. Tirant monografías No. 298. Tirant lo Blanch.

MEINI, Iván. (2005, Diciembre). Problemas de autoría y participación en la criminalidad estatal organizada. En Nuevo Foro Penal. No 68. Julio - Diciembre

MIR PUIG. (1998). Santiago. Derecho penal parte general. Quinta edición.Tec foto.

MIR PUIG, Santiago director; CASTIÑEIRA PLOU, Maria Teresa; LLOBET ANGLI, Mariona; MONTANER FERNANDEZ, Raquel. (2005). Comentarios a la jurisprudencia del Tribunal Supremo. Sección jurisprudencia. Universidad Pompeu Fabra. ADPCP. Vol LVIII.

ORTS BERENGUER, Enrique y GONZALEZ CUSSAC, José Luis. (2010). Compendio de Derecho Penal Pate General. Segunda Edición. Tirant lo Blanch.

QUINTERO OLIVARES, Gonzalo. (2007). Parte General del Derecho Penal. Segunda edición. Thomson aranzadi.

REYES ALVARADO, Yesid. (2005). Imputación objetiva. Temis. Tercera edición. Bogotá.

ROSO CAÑADILLAS, Raquel. (2002). Autoría y participación imprudente. Estudios de derecho penal. Editorial comares.

ROXIN, Claus. (1996). Derecho Penal parte general. Segunda edición. Civitas. 
ROXIN, Claus. (2007). La teoría del delito en la discusión actual. Grinley.

ROXIN, Claus. (2007). Autoría y dominio del hecho en el derecho penal. Séptima edición. Marcial Pons. 2007.

SAENZ CANTERO CAPARRÓS, José. (2001). La codelincuencia en los delitos imprudentes en el código penal de 1995. Marial Pons.

SCHUNEMANN, Bernd. (2007). Aspectos puntuales de la dogmática jurídico penal. Grupo editorial Ibáñez. Santo Tomás.

SILVA SANCHEZ, Jesús María. (2004). Estudios sobre los delitos de omisión. Editora jurídica grijley.

SILVA SANCHEZ, Jesús María; autoría delictiva en las estructuras organizadas. En SILVA SANCHEZ, Jesús María; SUAREZ GONZALEZ, Carlos. (2001). La dogmática Penal Frente a la criminalidad en la administración pública. Biblioteca de autores extranjero 7. Grijley. Instituto peruano de ciencias sociales.

SUAREZ SANCHEZ, Alberto. (2007). Autoría. Externado de Colombia.
TERRAGNI, Marco Antonio. (2008). Autor, partícipe y víctima en el delito culposo. Rubinzalculzoni editores.

VELASQUEZ VELASQUEZ, Fernando. (2010). Manual de derecho penal. Cuarta Cuarta edición. Ediciones jurídicas Andrés Morales.

VELASQUEZ VELASQUEZ, Fernando. (2007). Derecho Penal parte general. Cuarta edición. Comlibros.

WELZEN, Hans. (1956). Derecho Penal parte general. Roque Depalma Ed.

ZAFFARONI, Eugénio Raúl; ALAJIA, Alejandro; SLOKAR, Alejandro. (2006). Manual de Derecho Penal parte general. Segunda edición. Ediar y Temis.

\section{Páginas web}

Especiales Pirry "Riesgos y Peligros detrás de una cola perfecta; capítulos 1,2,3,4,5,6." Encontrado en la siguiente página web: http://www.youtube. com/watch?v=sVqONPAP39o consultado el día 10 de Diciembre de 2011. 